\title{
Epicardial Fat, Paracrine-mediated Inflammation and Atrial Fibrillation
}

\author{
Nora Rat'1,2, Adriana Mitre1, Szilamér Korodi1,2, István Benedek Jr¹,3, Erzsébet Lázár ${ }^{1,3}$, \\ Johanna Kéri1,3, Annamária Pakucs ${ }^{1,3}$, István Benedek1,3 \\ ${ }^{1}$ University of Medicine and Pharmacy, Tîrgu Mureș, Romania \\ ${ }^{2}$ Center of Advanced Research in Multimodality Cardiac Imaging, Cardio Med Medical Center, Tîrgu Mureș, Romania \\ ${ }^{3}$ Clinic of Hematology and Bone Marrow Transplantation Unit, Tîrgu Mureș, Romania
}

\section{CORRESPONDENCE}

\section{Adriana Mitre \\ Str. Gheorghe Marinescu nr. 38 \\ 540139 Tîrgu Mureș, Romania \\ Tel: +40 265215551 \\ E-mail: adimitre@yahoo.com}

\section{ARTICLE HISTORY}

Received: October 15, 2017

Accepted: December 10, 2017
Nora Rat • Str. Gheorghe Marinescu nr. 38, 540139 Tîrgu Mureș, Romania. Tel: +40 265215 551, E-mail: ratnora@gmail.com

Szilamér Korodi • Str. Gheorghe Marinescu nr. 38, 540139 Tîrgu Mureș, Romania. Tel: +40 265215551 E-mail: szilamerkorodi@yahoo.com.

István Benedek Jr • Str. Gheorghe Marinescu nr. 38, 540139 Tîrgu Mureș, Romania. Tel: +40 265215 551, E-mail: benedekistvan73@yahoo.com

Erzsébet Lázár • Str. Gheorghe Marinescu nr. 38 540139 Tîrgu Mures, Romania. Tel: +40 265215 551, E-mail: erzsebetlazarbenedek@gmail.com

Johanna Kéri • Str. Gheorghe Marinescu nr. 38 540139 Tîrgu Mures, Romania. Tel: +40 265215 551, E-mail: johannakeri@gmail.com

Annamária Pakucs • Str. Gheorghe Marinescu nr. 38 540139 Tîrgu Mureș, Romania. Tel: +40 265215 551, E-mail: pakucs.annamaria@gmail.com

István Benedek • Str. Gheorghe Marinescu nr. 38 540139 Tîrgu Mures, Romania. Tel: +40 265215 551, E-mail: istvan.benedek@umftgm.ro

\begin{abstract}
Atrial fibrillation is the most frequent arrhythmia in adults, becoming more frequent with age Recent clinical studies demonstrated that epicardial fat is linked with atrial fibrillation induction and recurrence. The arrhythmogenic mechanism consists in the fact that the epicardial adipose tissue is metabolically active, inducing local inflammation and enhancing the oxidative stress, which lead to atrial fibrillation as well as atherosclerosis. Having metabolic activity and secreting various anti- and pro-inflammatory biomarkers, the fat surrounding the heart has been linked to the complex process of coronary plaque vulnerabilization. This clinical update aims to summarize the role of epicardial adipose tissue in the pathogenesis, persistence, and severity of atrial fibrillation.
\end{abstract}

Keywords: atrial fibrillation, pericardial fat, inflammation, noninvasive cardiac imaging

\section{INTRODUCTION}

Atrial fibrillation (AF) is the most frequent rhythm disturbance, its incidence being higher with increasing age. ${ }^{1}$ It has been estimated that AF will affect around 18 million people in Europe by $2060 .^{2}$ There are a series of risk factors that can lead to development of AF including old age, level of physical activity, smoking, diabetes mellitus, arterial hypertension, heart failure, coronary heart disease, obstructive sleep apnea, and obesity. Both increased body mass index and epicardial fat volume have been associated with the risk of AF. ${ }^{3-6}$

Several studies have researched the association of epicardial adipose tissue (EAT) and the burden of coronary atherosclerosis. ${ }^{78}$ EAT presents various roles, including thermoregulation and mechanical protection of the heart's vascularization and innervation. On the other hand, having metabolic activity and secreting various anti- and pro-inflammatory biomarkers, the fat surrounding the heart has been linked to the destabilization process of coronary plaques. ${ }^{9,10}$ Furthermore, subjects with increased epicardial fat thickness or volume have 
an increased risk of major adverse cardiac events, as well as a higher risk for multi-vessel coronary artery disease, presenting also an increased calcium score, which is an established marker for the severity of coronary artery disease. ${ }^{11-14}$ This clinical update aims to summarize the role of EAT in the pathogenesis, persistence, and severity of atrial fibrillation.

\section{EPICARDIAL FAT, ATRIAL REMODELING AND ARRHYTHMOGENESIS}

A series of studies have confirmed the association of EAT with the presence of AF. ${ }^{15}$ There are no intervening structures between EAT and the myocardium. EAT is overlying the right ventricle, coronary arteries, left ventricle apex, and the atria. ${ }^{16}$ EAT is a metabolically active tissue, and it has paracrine effects on the atrial myocardium by secreting inflammatory mediators, including C-reactive protein, IL-6, IL-8, IL-1b, and TNF-a, which induce local inflammation and enhance oxidative stress. ${ }^{17-23}$ EAT also secretes adipokines, such as adipokine activin A and matrix metalloproteinases 2 and 7, which have marked pro-fibrotic effects, inducing atrial fibrosis. ${ }^{24,25}$ In addition, increased EAT volume is associated with adipocyte infiltration into the underlying atrial myocardium, resulting in atrial structural changes. ${ }^{26-28}$ EAT modulates the activity of both parasympathetic and sympathetic autonomic nervous systems, primarily shortening the atrial refractory period, increasing the tendency for AF. ${ }^{29,30}$ Local inflammation, oxidative stress, adipocyte infiltration, and autonomic nervous system modulation can lead to electrical and structural remodeling of the atrial tissue, contributing to development of AF.

\section{EPICARDIAL FAT, AND TYPE AND SEVERITY OF ATRIAL FIBRILLATION}

Numerous studies have demonstrated the association between EAT and the subtype of AF - paroxysmal and persistent, respectively. ${ }^{31}$ Recent clinical studies have found a direct positive correlation between EAT and the persistence of atrial fibrillation. Patients with increased EAT were shown to have a more severe AF burden and were more likely to present persistent or chronic atrial fibrillation, as well as a higher rate of AF-related complications. ${ }^{32-36}$ EAT has also been associated with left atrium (LA) volume, while no such association was encountered between systemic adiposity and LA volumes, suggesting the independent effect of pericardial visceral adiposity on the chronicity and severity of AF. ${ }^{33}$ The presence of AF, AF chronicity, AF symptom severity, and recurrence of AF af- ter ablation procedures have all been demonstrated to have significant associations with epicardial fat volumes, even after multivariate adjustments for body mass index, body surface area, and visceral adiposity. ${ }^{33}$

\section{EPICARDIAL FAT DETERMINATION WITH NONINVASIVE IMAGING TECHNIQUES}

EAT can be quantified with the use of noninvasive imaging techniques such as $2 \mathrm{D}$ transthoracic echocardiography (TTE), native cardiac computed tomography (CT), and magnetic resonance imaging (MRI). 37,38

Transthoracic echocardiography is a low-cost, highly accessible noninvasive method to assess the thickness of EAT. ${ }^{37}$ The method has been proved to be as useful as CT or MRI in the quantification of EAT. ${ }^{37,39}$ On TTE, pericardial fat $(\mathrm{PF})$ is presented as a hypoechogenic space between the myocardium and pericardium, and it should be considered increased if its thickness is over $5 \mathrm{~mm}$ during the end-diastolic period. The assessment is performed from the parasternal long axis view at the level of the free wall of the right ventricle. ${ }^{37,40-43}$ Disadvantages of TTE include the high inter- and intra-observer variability, difficult image windows, and the uneven distribution of PF that could vary between the diastole and systole. ${ }^{37,44}$

Cardiac CT is a more precise technique for the assessment of EAT volume, total area, and thickness. Pericardial fat, which includes all fatty tissue within the pericardial sac, is illustrated with an image display threshold of -190 to -30 Hounsfield Units (HU). ${ }^{37,44,45}$ CT advantages include the excellent intra-ob $\neg$ server and inter-observer variability and high resolution, and it also provides precise quantitative assessment of both volume and thickness of the pericardial and epicardial adipose tissue. ${ }^{37,44-47}$ Concomitantly, CT can evaluate the presence of coronary artery disease and allows the measurement of the left atrium volume. ${ }^{37,44}$ The main disadvantages of computed tomography are high costs and the exposure to ionizing radiation. ${ }^{37,44}$

Cardiac magnetic resonance imaging (CMRI) is the gold-standard imaging investigation for the assessment of the fatty tissue that surrounds the heart. ${ }^{37} \mathrm{CMRI}$ is a validated imaging method not only for the quantification of the adipose tissue that overlies the ventricular myocardium, but also for measuring the pericardial fat located in the vicinity of the atria, which might be more relevant in regard to the pathogenesis of atrial arrhythmias due to its close contact with the atrial myocardium. ${ }^{44,48}$

CMRI presents multiple benefits that include the quantitative assessment of left atrial volume for evaluating the functional and structural features of the ventricles and the 
degree of fibrosis in the ventricular and atrial myocardium, which can all offer various information on the pathogenesis of $\mathrm{AF}$ and other arrhythmias. ${ }^{48}$

Besides allowing the acquisition of good quality images of the heart and the possibility of volumetric measurements on the pericardial adipose tissue, without additional exposure to radiation, CMRI is the single imaging modality that has been validated ex vivo for quantifying the epicardial fat. The main disadvantages of the method are the lack of feasibility in an emergency clinical setting and the increased costs. ${ }^{37,44,48}$

\section{EPICARDIAL FAT - A NOVEL RISK PREDICTION MARKER}

Epicardial adipose tissue has been linked with several acute coronary syndrome risk prediction scores. ${ }^{49,50-52}$ The GRACE (Global Registry of Acute Coronary Events) score, the Syntax score for the severity of coronary lesions, and the clinical TIMI score for the prediction of adverse coronary events, have all shown positive correlations with an increased epicardial fat volume or thickness. ${ }^{49,51,53}$ Similarly, an increased amount of fatty tissue surrounding the heart has been shown to predict major adverse cardiac events including myocardial infarction and death in subjects with acute coronary syndromes, as well as in those with suspected coronary artery disease. ${ }^{54-56}$ The link between atrial fibrillation and EAT could be explained by the concomitant coronary artery disease of these patients. However, new research has shown that there is an association between $\mathrm{AF}$ and epicardial fat in subjects who are free of cardiovascular disease, independent of classical cardiovascular risk factors and coronary atherosclerosis. ${ }^{57}$ The adipose tissue surrounding the heart has been shown to be independently associated with the incidence, severity, and recurrence of AF, but was also found to be a significant predictor for AF recurrence after catheter ablation for persistent $\mathrm{AF}$ and poorer ablation outcomes. ${ }^{58,59}$ Further research is needed to prove the risk stratification properties of epicardial fat in atrial fibrillation, which could improve outcomes in these patients, beyond the already existing risk prediction clinical tools.

\section{CONCLUSION}

Epicardial adipose tissue has emerged as a novel biomarker reflecting the cardiovascular risk. Recent research on the pathogenesis and severity of atrial fibrillation has found PF as an independent predictor for the burden, persistence, and recurrence of atrial fibrillation, as well as for its related complications. Due to its noninvasive quantification, epicardial adipose tissue could represent a future imaging biomarker to be included among AF risk prediction tools.

\section{CONFLICT OF INTEREST}

Nothing to declare.

\section{REFERENCES}

1. Fuster V, Ryden LE, Cannom DS, Crijns HJ, et al. ACC/AHA/ESC 2006 Guidelines for the Management of Patients with Atrial Fibrillation: a report of the American College of Cardiology/American Heart Association Task Force on Practice Guidelines and the European Society of Cardiology Committee for Practice Guidelines (Writing Committee to Revise the 2001 Guidelines for the Management of Patients With Atrial Fibrillation): developed in collaboration with the European Heart Rhythm Association and the Heart Rhythm Society. Circulation. 2006:114:e257-e354.

2. Krijthe BP, Kunst A, Benjamin EJ, et al. Projections on the number of individuals with atrial fibrillation in the European Union, from 2000 to 2060. Eur Heart J. 2013;34:2746-2751.

3. Wang TJ, Parise H, Levy D, et al. Obesity and the risk of new-onset atrial fibrillation. JAMA. 2004:292:2471-2477.

4. Kenchaiah S, Evans JC, Levy D, et al. Obesity and the risk of heart failure. N Engl J Med. 2002:347:305-313.

5. Wanahita N, Messerli FH, Bangalore S, Gami AS, Somers VK, Steinberg JS. Atrial fibrillation and obesity - results of a meta-analysis. Am Heart J. 2008:155:310-315

6. Thanassoulis G, Massaro JM, O'Donnell CJ, et al. Pericardial fat is associated with prevalent atrial fibrillation: the Framingham Heart Study. Circ Arrhythm Electrophysiol. 2010;3:345-350

7. Doesch C, Jochims J, Streitner F, et al. Novel prognostic markers derived from cardiovascular magnetic resonance imaging in patients with stable chronic coronary artery disease. InVivo. 2015;29:737-747.

8. Opincariu D, Mester A, Dobra M, et al. Prognostic value of epicardial fat thickness as a marker of increased inflammatory status in patients with type 2 diabetes mellitus and acute myocardial infarction. Journal of Cardiovascular Emergencies. 2016;2:11-18.

9. Mahabadi A, Berg M, Lehmann N, et al. Association of Epicardial Fat With Cardiovascular Risk Factors and Incident Myocardial Infarction in the General Population: The Heinz Nixdorf Recall Study. J Am Coll Cardiol. 2013;61:1388-1395

10. Nakanishi K, Fukuda S, Tanaka A, et al. Persistent epicardial adipose tissue accumulation is associated with coronary plaque vulnerability and future acute coronary syndrome in nonobese subjects with coronary artery disease. Atherosclerosis. 2014;237:353-360

11. Tamarappoo B, Dey D, Shmilovich H, et al. Increased pericardial fat volume measured from non-contrast CT predicts myocardial ischemia by SPECT. JACC Cardiovasc Imaging. 2010;3:1104-e1112.

12. Doesch $C$, Süselbeck T, Haghi D, et al. The relationship between the severity of coronary artery disease and epicardial adipose tissue depends on the left ventricular function. PLoS One. 2012;7:e48330.

13. Nakanishi K, Fukuda S, Tanaka A, et al. Persistent epicardial adipose tissue accumulation is associated with coronary plaque vulnerability and future acute coronary syndrome in nonobese subjects with coronary artery disease. Atherosclerosis. 2013;237:353-360.

14. Fukamachi D, Higuchi Y, Hiro T, et al. Association between the epicardial adipose tissue thickness and the presence of multivessel disease in patients with acute myocardial infarction. J Atheroscler Thromb. 2014;2:144-151.

15. Wong CX, Sun MT, Odutayo A, et al. Associations of Epicardial, Abdominal, and Overall Adiposity with Atrial Fibrillation. Circ Arrhythm Electrophysiol. 2016; pii:e00437.

16. lacobellis G, Corradi D, Sharma AM. Epicardial adipose tissue: anatomic, biomolecular and clinical relationships with the heart. Nat Clin Pract Cardiovasc Med. 2005;2:536-543.

17. Sawaya SE, Rajawat YS, Rami TG, et al. Downregulation of connexin40 and increased prevalence of atrial arrhythmias in transgenic mice with cardiac-restricted overexpression of tumor necrosis factor. Am J Physiol Heart Circ Physiol. 2007;292:H1561-H1567. 
18. Marcus GM, Whooley MA, Glidden DV, Pawlikowska L, Zaroff JG, Olgin JE. Interleukin- 6 and atrial fibrillation in patients with coronary artery disease: data from the Heart and Soul Study. Am Heart J. 2008;155:303-309.

19. Tselentakis EV, Woodford E, Chandy J, Gaudette GR, Saltman AE. Inflammation effects on the electrical properties of atrial tissue and inducibility of postoperative atrial fibrillation. J Surg Res. 2006;135:68-75.

20. Chung MK, Martin DO, Sprecher D, et al. C-reactive protein elevation in patients with atrial arrhythmias: inflammatory mechanisms and persistence of atrial fibrillation. Circulation. 2001;104:2886-2891.

21. Malouf JF, Kanagala R, Al Atawi FO, et al. High sensitivity Creactive protein: a novel predictor for recurrence of atrial fibrillation after successful cardioversion. J Am Coll Cardiol. 2005:46:1284-1287.

22. Aviles RJ, Martin DO, Apperson-Hansen C, et al. Inflammation as a risk factor for atrial fibrillation. Circulation. 2003;108:3006-3010.

23. Rotter $\mathrm{M}$, Jais $\mathrm{P}$, Vergnes $\mathrm{MC}$, et al. Decline in C-reactive protein after successful ablation of long-lasting persistent atrial fibrillation. J Am Coll Cardiol. 2006;47:1231-1233.

24. Sacks HS, Fain JN. Human epicardial adipose tissue: a review. Am Heart J. 2007;153:907-917.

25. Verheule S, Sato T, Everett TT, et al. Increased vulnerability to atrial fibrillation in transgenic mice with selective atrial fibrosis caused by overexpression of TGF-beta1. Circ Res. 2004;94:1458-1465.

26. Hatem SN, Sanders P. Epicardial adipose tissue and atrial fibrillation. Cardiovasc Res. 2014;102:205-213.

27. Mahajan R, Lau DH, Brooks AG, et al. Electrophysiological, electroanatomical and structural remodeling of the atria as a consequence of sustained obesity. J Am Coll Cardiol. 2015;66:1-11.

28. Shirani J, Berezowski K, Roberts WC. Quantitative measurement of normal and excessive (cor adiposum) subepicardial adipose tissue, its clinical significance, and its effect on electrocardiographic QRS voltage. Am J Cardiol. 1995; 76:414-418

29. Nakagawa H, Scherlag BJ, Patterson E, Ikeda A, Lockwood D, Jackman WM. Pathophysiologic basis of autonomic ganglionated plexus ablation in patients with atrial fibrillation. Heart Rhythm. 2009;6:S26-S34.

30. Schauerte P, Scherlag BJ, Pitha J, et al. Catheter ablation of cardiac autonomic nerves for prevention of vagal atrial fibrillation. Circulation. 2000;102:2774-2780.

31. Gaeta M, Bandera F, Tassinari F, et al. Is epicardial fat depot associated with atrial fibrillation? A systematic review and metaanalysis. Europace. 2017:19:747-752.

32. Al-Rawahi M, Proietti R, Thanassoulis G. Pericardial fat and atrial fibrillation: Epidemiology, mechanisms and interventions. Int J Cardiol. 2015;195:98103.

33. Wong CX, Abed HS, Molaee P, et al. Pericardial fat is associated with atrial fibrillation severity and ablation outcome. J Am Coll Cardiol. 2011;57:17451751.

34. Batal O, Schoenhagen P, Shao M, et al. Left atrial epicardial adiposity and atrial fibrillation. Circ Arrhythm Electrophysiol. 2010;3:230-236.

35. Greif M, von Ziegler F, Wakili R, et al. Increased pericardial adipose tissue is correlated with atrial fibrillation and left atrial dilatation. Clin Res Cardiol. 2013:102:555-562.

36. Nagashima K, Okumura Y, Watanabe I, et al. Association between epicardial adipose tissue volumes on 3-dimensional reconstructed CT images and recurrence of atrial fibrillation after catheter ablation. Circ $J$. 2011;75:2559-2565.

37. Benedek T, Rat N, Hodas R, Opincariu D, Mester A, Benedek I. The Assessment of Epicardial Adipose Tissue in Acute Coronary Syndrome Patients. A Systematic Review. Journal of Cardiovascular Emergencies. 2017;3:18-29.

38. Bertaso A, Bertol D, Duncan B, Foppa M. Epicardial Fat: Definition, Measurements, and Systematic Review of Main Outcomes. Arq Bras Cardiol. 2013;101:18-28.

39. lacobellis G, Assael $F$, Ribaudo $M$, et al. Epicardial fat from echocardiography: a new method for visceral adipose tissue prediction. Obes Res. 2003:11:304-310
40. Iacobellis G, Willens H. Echocardiographic Epicardial Fat: A Review of Research and Clinical Applications. J Am Soc Echocardiogr. 2009;22:13111319

41. lacobellis G, Willens H, Barbaro G, Sharma AM. Threshold values of high risk echocardiographic epicardial fat thickness. Obesity (Silver Spring). 2008:16:887-892

42. lacobellis G, Singh N, Wharton S, Sharma A. Substantial changes in epicardial fat thickness after weight loss in severely obese subjects. Obesity (Silver Spring). 2008;16:1693-1697.

43. Jeong J, Jeong M, Yun K, et al. Echocardiographic epicardial fat thickness and coronary artery disease. Circ J. 2007;71:536-539.

44. Al Chekakie MO, Akar JG. Epicardial Fat and Atrial Fibrillation: A Review. J Atr Fibrillation. 2012;4:483.

45. Sarin S, Wenger C, Marwaha A, et al. Clinical significance of epicardial fat measured using cardiac multislice computed tomography. Am J Cardiol. 2008:102:767-771.

46. Tsao HM, Hu WC, Wu MH, et al. Quantitative analysis of quantity and distribution of epicardial adipose tissue surrounding the left atrium in patients with atrial fibrillation and effect of recurrence after ablation. $A m \mathrm{~J}$ Cardiol. 2011:107:1498-1503.

47. Al Chekakie MO, Welles CC, Metoyer R, et al. Pericardial fat is independently associated with human atrial fibrillation. J Am Coll Cardiol. 2010;56:784-788

48. Mahajan R, Kuklik P, Grover S, et al. Cardiovascular magnetic resonance of total and atrial pericardial adipose tissue: a validation study and development of a 3 dimensional pericardial adipose tissue model. $J$ Cardiovasc Magn Reson. 2013:15:73.

49. Altun B, Colkesent Y, Gazi E, et al. Could Epicardial Adipose Tissue Thickness by Echocardiography be Correlated with Acute Coronary Syndrome Risk Scores. Echocardiography. 2013;30:1130-1134.

50. Gul I, Zungur M, Aykan A, et al. The relationship between GRACE score and Epicardial Fat thickness in non-STEMI Patients. Arq Bras Cardiol. 2016;106:194-200

51. Ozcan F, Turak O, Canpolat U, et al. Association of epicardial fat thickness with TIMI risk score in NSTEMI/USAP patients. Herz. 2013;39:755-760.

52. Zencirci E, Zencirci A, Degirmencioglu A, et al. The relationship between epicardial adipose tissue and ST-segment resolution in patients with acute ST-segment elevation myocardial infarction undergoing primary percutaneous coronary intervention. Heart Vessels. 2014:2:147-153.

53. Wang T, Liu Q, Liu C, et al. Correlation of Echocardiographic Epicardial Fat Thickness with Severity of Coronary Artery Disease in Patients with Acute myocardial infarction. Echocardiography. 2014;31:1177-1181.

54. Tanindi A, Erkan A, Ekici B. Epicardial adipose tissue thickness can be used to predict major adverse cardiac events. Coron Artery Dis. 2015;26:686-691

55. Hajsadeghi F, Nabavi $\mathrm{V}$, Bhandari A, et al. Increased epicardial adipose tissue is associated with coronary artery disease and major adverse cardiovascular events. Atherosclerosis. 2014;237:486-489.

56. Cheng V, Dey D, Tamarappoo B, et al. Pericardial fat burden on ECG-gated non-contrast $\mathrm{CT}$ in asymptomatic patients who subsequently experience adverse cardiovascular events. JACC Cardiovasc Imaging. 2010;3:352360.

57. Bos D, Vernooij MW, Shahzad R, et al. Epicardial Fat Volume and the Risk of Atrial Fibrillation in the General Population Free of Cardiovascular Disease. JACC Cardiovasc Imaging. 2017;10:1405-1407.

58. Kim TH, Park J, Park JK, et al. Pericardial fat volume is associated with clinical recurrence after catheter ablation for persistent atrial fibrillation, but not paroxysmal atrial fibrillation: an analysis of over 600 patients. Int $J$ Cardiol. 2014;176:841-846.

59. Wong CX, Abed HS, Molaee P, et al. Pericardial fat is associated with atrial fibrillation severity and ablation outcome. J Am Coll Cardiol. 2011;57:17451751. 